\title{
SELENOT Deficiency in the Mouse Brain Impacts Catecholaminergic Neuron Density: An Immunohistochemical, in situ Hybridization and 3D Light-Sheet Imaging Study
}

\author{
David Godefroy ${ }^{a}$ Loubna Boukhzar ${ }^{a}$ Ben Yamine Mallouki ${ }^{a}$ \\ Emmanuelle Carpentier ${ }^{\mathrm{a}}$ Christophe Dubessy ${ }^{\mathrm{a}}$ Fatiha Chigr $^{\mathrm{b}} \quad$ Yves Tillet $^{\mathrm{c}}$ \\ Youssef Anouar ${ }^{\text {a }}$ \\ aUNIROUEN, INSERM U1239, Neuronal and Neuroendocrine Differentiation and Communication Laboratory, \\ Institute for Research and Innovation in Biomedicine (IRIB), Normandie Univsity, Rouen, France; bioengineering \\ Laboratory, Faculty of Sciences and Techniques, Sultan Moulay Slimane University, Beni Mellal, Morocco; \\ 'Physiologie de la Reproduction et des Comportements, UMR 085 INRAE, CNRS 7247, IFCE, Centre INRAE Val de \\ Loire, Université de Tours, Nouzilly, France
}

\section{Keywords}

Selenoprotein T · Tyrosine hydroxylase - Catecholaminergic neuron $\cdot$ iDISCO $+\cdot$ Light-sheet imaging

\begin{abstract}
Background: Selenoprotein T (SELENOT), a PACAP-regulated thioredoxin-like protein, plays a role in catecholamine secretion and protects dopaminergic neurons. However, the role of SELENOT in the establishment of the catecholaminergic (CA) neuronal system is not known yet. Methods: We analyzed by immunohistochemistry and RNAscope in situ hybridization the distribution of SELENOT and the expression of its $m R N A$, respectively. In addition, 3D imaging involving immunostaining in toto, clearing through the iDISCO+ method, acquisitions by light-sheet microscopy, and processing of 3D images was performed to map the CA neuronal system. A semi-automatic quantification of 3D images was carried out. Results: SELENOT protein and mRNA are widely distributed in the mouse brain, with important local varia-
\end{abstract}

tions. Three-dimensional mapping, through tyrosine hydroxylase (TH) labeling, and semi-automated quantification of CA neurons in brain-specific SELENOT knockout mice showed a significant decrease in the number of TH-positive neurons in the area postrema (AP-A2), the A11 cell group (A11), and the zona incerta (ZI-A13) of SELENOT-deficient females, and in the hypothalamus (Hyp-A12-A14-A15) of SELENOT-deficient females and males. Conclusion: These results showed that SELENOT is diffusely expressed in the mouse brain and that its deficiency impacts $C A$ neuron distribution in different brain areas including Hyp-A12-A14-A15, in both male and female mice.

(c) 2022 S. Karger AG, Base

\section{Introduction}

Catecholamines control various biological functions such as stress, emotions, learning, and motor function [1-4]. Catecholaminergic (CA) neurons produce the 
neurotransmitters noradrenaline (NA), adrenaline, or dopamine (DA) through a series of enzymatic modifications of the amino-acid precursor tyrosine. These neurons share the first two steps of the catecholamine-synthesis pathway catalyzed by tyrosine hydroxylase (TH) and L-Dopa decarboxylase, and that leads to DA. Adrenergic and NA neurons share a third step catalyzed by DA $\beta$-hydroxylase that leads to NA, and only adrenergic neurons which constitute a minor population of CA neurons express phenylethanolamine $\mathrm{N}$-methyltransferase for adrenaline synthesis [5]. The distribution of CA neuronal groups described for the first time in the 1960s did not always correspond to defined anatomical structures, which led Dahlstrom and Fuxe [6] to create a nomenclature to name the first twelve CA cell groups designated from A1 to A12 located from the medulla oblongata (MO) to the Hyp. Later, the number of CA cell groups was incremented from twelve to twenty, with seventeen groups (A1-A17) distributed in the diencephalon, the olfactory bulb, and the retina to which were added 3 groups of adrenergic cells named $\mathrm{C} 1-\mathrm{C} 3$ [5]. In addition, the number of cells within CA groups varies among mammalian species [7]. Understanding the mechanisms leading to the occurrence of the different groups of CA neurons in the brain is necessary to better decipher the role of these neurons in physiological situations but also in several pathological conditions involving CA neurotransmitters.

Like other cell types endowed with a secretory pathway, CA neurons rely on the homeostasis of the endoplasmic reticulum (ER) to appropriately synthesize and deliver their secretory products. It is now well established that ER proteostasis regulation is altered in neurodegenerative diseases, and accumulating evidence indicates that these mechanisms also contribute to neuronal physiology, impacting brain development and function [8]. While mild insults increase the activity of protective chaperones and other proteostatic cues in the ER, prolonged cell stress or insufficient adaptive response causes cell death as it is the case in Parkinson's disease where dopaminergic neurons are affected [9]. We have recently shown that selenoprotein $\mathrm{T}$ (SELENOT), a member of ER selenoproteins involved in proteostasis and stimulated by the neuropeptide PACAP in neuroendocrine cells [10, 11], plays a pivotal role in hormone secretion, neuron survival, and response to stress [10,12-14]. Conditional disruption of the SELENOT gene in nerve cells leads to morphological changes during the early stages of cerebral postnatal development, and behavioral alterations including hyperactivity in adulthood [13]. We also found that SELENOT protects dopaminergic neurons in animal models of Parkinson's disease $[12,15]$. These data suggest that the proteostatic action of SELENOT in the ER is instrumental to CA neuron development and function. However, there is currently no study reporting on the role of a selenoprotein or SELENOT in particular in the establishment of the brain cytoarchitecture at the global level or at a neuronal population level such as the CA neuronal system.

Neurons that have a CA phenotype were historically the first transmitter systems to be described in detail, because of the ease of their detection by formaldehyde-induced fluorescence [16]. Recent significant evolution has been made in the methods of histological studies initially developed by Falck et al. [17]. Indeed, although the immunolabeling of in toto organs such as the spinal cord [18] and postnatal brains or embryos $[19,20]$ has been developed since 1980, today new immunolabeling protocols significantly improved the in toto staining of adult samples [21]. Associating these in toto immunolabeling approaches with clearing techniques [21-23] and light-sheet microscopy imaging $[24,25]$ opens a new dimension to histological studies [26]. In the present study, the choice of this three-dimensional analytical approach associated with a conventional immunohistochemical approach and the RNAscope in situ hybridization technique is made to characterize the central CA neuronal system of mice lacking the SELENOT gene in nerve cells (Nes-Cre/SELENOT $\left.^{f l f f}\right)$ [13]. This allowed us to establish the differential role of SELENOT in the spatial distribution of CA neuron populations in the female and male mouse brain.

\section{Materials and Methods}

\section{Animals}

SELENOT-floxed (SELENOT ${ }^{f l f l}$ ) mice were generated at the Mouse Clinical Institute (Illkirch, France). To selectively silence SELENOT gene in neural cells, SELENOT ${ }^{f l f l}$ mice were bred with $\mathrm{Tg}$ (Nestin-Cre) $1 \mathrm{Kln}^{+/-}$knock-in mice $[12,13]$, which were acquired from the Jackson Laboratory (Bar Harbor, ME, USA). Absence of SELENOT protein in the of brain Nes-Cre/SELENOT ${ }^{f l f l}$ mice was previously established $[12,13]$. It is known that nestindriven Cre could exhibit some activity in a few peripheral tissues. However, the transgenic line Tg (Nestin-Cre) $1 \mathrm{Kln}^{+/-}$used has been developed by placing the Cre recombinase under the control of a rat nestin promoter and the nervous system-specific enhancer present in the second intron. This promoter expresses Cre recombinase in neuronal and glial cell precursors. For experiments, animals were group-housed in a climate-controlled colony with a 12-h light/dark cycle (light on at 07:00 a.m.) and access to food and water ad libitum. Adult male and female mice between 3 and 12 months of age were used throughout this study. 


\section{RNA Scope-Fluorescent in situ Hybridization}

Mice were anesthetized using a solution of ketamine $(100 \mathrm{mg} /$ $\mathrm{kg}$ ) and xylazine $(10 \mathrm{mg} / \mathrm{kg})$, and perfused with sterile phosphatebuffered saline (PBS) followed by sterile paraformaldehyde (PFA) $4 \%$. Brains were dissected and post-fixed in PFA $4 \%$ overnight at $4^{\circ} \mathrm{C}$. Cryoprotection was performed through immersion in sterile sucrose $15 \%$ and $30 \%$. Brains were frozen in isopentane in dry ice and stored at $-80^{\circ} \mathrm{C}$. Tissues were sectioned into $10-12-\mu \mathrm{m}$ slices with a cryostat. Slices were washed $5 \mathrm{~min}$ in sterile PBS and heated at $60^{\circ} \mathrm{C}$ in a dedicated oven (ACD HybEZ ${ }^{\mathrm{TM}}$ II Hybridization System [220v] with ACD EZ-Batch Slide System; Bio-Techne, Rennes, France) under Bake mode for $30 \mathrm{~min}$, and then post-fixed for 15 min with sterile PFA 4\%. Slices were dehydrated in graded solutions of ethanol at $50 \%, 70 \%$, and twice $100 \%$ during $5 \mathrm{~min}$ for each bath. Slices were covered with $\mathrm{H}_{2} \mathrm{O}_{2}$ for 5 min and washed with distilled $\mathrm{H}_{2} \mathrm{O}$ two times. Slices were submerged for $10 \mathrm{~s}$ in distilled water at $99^{\circ} \mathrm{C}$ and 5 min in RNAscope 1X Target Retrieval Reagent (ACD Bio-Techne) at $99^{\circ} \mathrm{C}$. Slides were rinsed for $15 \mathrm{~s}$ in distilled water at room temperature, submerged $3 \mathrm{~min}$ in ethanol 100\% and dried at room temperature. Slices were covered with protease RNAscope (ACD Bio-Techne) for $30 \mathrm{~min}$ at $40^{\circ} \mathrm{C}$ and washed with distilled water two times. Hybridization was performed with $50 \mu \mathrm{L} /$ slice of RNAscope ${ }^{\circledR}$ probe mix (probe C1-TH targeting the sequence 4831603 of NM_009377.1 - Mm-Th mRNA, and probe C2-SELENOT targeting the sequence 1428-3520 of NM_001040396.3 - MmSELENOT mRNA, ACD Bio-Techne) for $2 \mathrm{~h}$ at $40^{\circ} \mathrm{C}$. Control probes were as follows: ubiquitin $\mathrm{C}$ gene, peptidylprolyl isomerase $\mathrm{B}$ (PPIB) gene and RNA polymerase II subunit gene were used as positive probes while the E. coli gene 4-hydroxy-tetrahydrodipicolinate reductase was used as a negative control. After hybridization, slices were covered with RNAscope Multiplex FL v2 Amp 1 during $30 \mathrm{~min}$ at $40^{\circ} \mathrm{C}$ and washed at room temperature with RNAscope wash buffer two times, and with RNAscope Multiplex FL v2 Amp 2 for $30 \mathrm{~min}$ at $40^{\circ} \mathrm{C}$ and washed at room temperature with RNAscope wash buffer two times, and with RNAscope Multiplex FL v2 Amp 3 for $15 \mathrm{~min}$ at $40^{\circ} \mathrm{C}$ and washed at room temperature with RNAscope wash buffer two times, (RNAscope Multiplex FL v2 Amp 1, 2, 3: RNAscope ${ }^{\circledR}$ Multiplex Fluorescent Reagent Kit v2; ACD Bio-Techne). After amplification, the staining steps were carried out sequentially. Slices were covered with RNAscope Multiplex FL v2 HRP-C1 (ACD Bio-Techne) for $15 \mathrm{~min}$ at $40^{\circ} \mathrm{C}$ and washed at room temperature with RNAscope wash buffer two times, then covered by $80 \mu \mathrm{L}$ of Opal 520 at 1/1,500 (Opal 520 reagent pack, FP1487001KT; Akoya Biosciences, Malborough, MA, USA) for 30 min at $40^{\circ} \mathrm{C}$ and washed at room temperature with RNAscope wash buffer two times, followed by staining of $\mathrm{C} 1$ to block with HRP blocker (ACD Bio-Techne) for $15 \mathrm{~min}$ at $40^{\circ} \mathrm{C}$ and washed at room temperature with RNAscope wash buffer two times. Slices were covered by $80 \mu \mathrm{L}$ of Opal 650 at 1/1,000 (Opal 650 reagent pack, Akoya Biosciences) for $30 \mathrm{~min}$ at $40^{\circ} \mathrm{C}$ and washed at room temperature with RNAscope wash buffer two times, and followed by staining of $\mathrm{C} 2$ to block with HRP blocker (ACD Bio Techne) for 15 min at $40^{\circ} \mathrm{C}$ and washed at room temperature with RNAscope wash buffer two times. Staining of the nuclei was done with RNAscope DAPI (ACD Bio-Techne), and the slides were mounted with Fluoromount (Sigma-Aldrich, St. Louis, MO, USA).

\section{Tissue Immunostaining}

Fixed tissues were sectioned in sagittal orientation into 10-12$\mu \mathrm{m}$ slices with a cryostat. The sections were post-fixed $30 \mathrm{~min}$ in
PFA 4\% then washed three times with PBS. Samples were incubated with $1 \%$ donkey serum diluted in $1 \%$ bovine serum albumin and $0.3 \%$ Triton X-100 in PBS for $2 \mathrm{~h}$ at room temperature and exposed overnight at $4^{\circ} \mathrm{C}$ to primary antibodies, including rabbit anti-SELENOT diluted 1:200 [27] and sheep anti-TH diluted 1:5,000. Sheep anti-TH antibodies were raised against rat $\mathrm{TH}$ purified from rat pheochromocytoma cells according to a protocol previously described [28]. This antibody reproduced neuronal TH immunostainings previously described in the literature. Immunostaining was visualized using Alexa 594-conjugated secondary anti-rabbit antibodies diluted 1:200 (Invitrogen, Saint Aubin, France) or Alexa 647-conjugated secondary anti-sheep antibodies diluted 1:200 (Interchim, Montluçon, France). Nuclei were stained with 1 $\mu \mathrm{g} / \mathrm{mL}$ 4,6- diamino-2-phenylindole diluted 1:1,000 (DAPI; Sigma-Aldrich) in PBS prior to mounting the slides with PBS/glycerol 50/50.

\section{Whole Brain Immunostaining}

Mice were anesthetized using a solution of ketamine (100 mg/ $\mathrm{kg}$ ) and xylazine $(10 \mathrm{mg} / \mathrm{kg})$, and perfused with PBS followed by PFA 4\%. Brains were dissected and post-fixed in PFA 4\% overnight at $4^{\circ} \mathrm{C}$. Brains were pretreated with methanol before immunostaining and washed in PBS for $1 \mathrm{~h}$ twice, then in $20-40-60-80 \%$ methanol (in $\mathrm{H} 2 \mathrm{O}$ ) and $100 \%$ methanol twice for $1 \mathrm{~h}$. They were then bleached with $3 \% \mathrm{H}_{2} \mathrm{O}_{2}$ in $100 \%$ methanol overnight at $4^{\circ} \mathrm{C}$ in the dark without shaking. Organs were rehydrated successively in $80-60-40-20 \%$ methanol, and PBS, each step for $1 \mathrm{~h}$ before staining procedures. Pretreated brains were incubated in a permeabilization solution containing $0.2 \%$ Triton X-100, 20\% DMSO, $0.3 \mathrm{M}$ glycine in $\mathrm{PBS}$ at $37^{\circ} \mathrm{C}$ for 2 days, with shaking. Then, the organs were transferred in a blocking solution ( $0.2 \%$ Triton X-100, $6 \%$ donkey serum in PBS) at $37^{\circ} \mathrm{C}$ for 2 days with shaking. The organs were then washed in a solution of PBS containing $0.2 \%$ Tween-20, $10 \mu \mathrm{g} / \mathrm{mL}$ heparin for 1 day and half, and incubated with the primary antibody (rabbit anti-TH; Sigma, Saint Quentin Fallavier, France), diluted 1:300 in the incubation solution containing $0.2 \%$ Tween-20, 5\% DMSO, $10 \mu \mathrm{g} / \mathrm{mL}$ heparin, 3\% donkey serum in PBS, for 7 days at $37^{\circ} \mathrm{C}$ with shaking. The samples then were washed with the washing solution described above for 1 day, and then incubated with secondary antibodies (donkey anti-rabbit Alexa Fluor 647, Jackson ImmunoResearch; Interchim, Montluçon, France) diluted 1:500 in the incubation solution for 7 days at $37^{\circ} \mathrm{C}$ with shaking. Finally, the organs were washed in the washing solution for 1 day. Controls for the $\mathrm{TH}$ immunoreaction have been performed previously and showed no false immunostaining $[26,29,30]$.

\section{Clearing Procedure}

Tissues were cleared with the following iDISCO+ protocol. First, the samples were dehydrated in methanol $/ \mathrm{H}_{2} \mathrm{O}$ solution $(20 \%, 40 \%, 60 \%$, and $80 \% 1 \mathrm{~h}$ each) and $100 \%$ methanol for $1 \mathrm{~h}$ twice with shaking. The samples were then incubated overnight in 1 volume of $100 \%$ methanol and 2 volumes of $100 \%$ dichloromethane anhydrous (Sigma-Aldrich), and washed twice for $20 \mathrm{~min}$ in $100 \%$ dichloromethane with shaking. Finally, the samples were incubated in $100 \%$ dibenzyl ether (Sigma-Aldrich) for at least $3 \mathrm{~h}$ with shaking before imaging. 


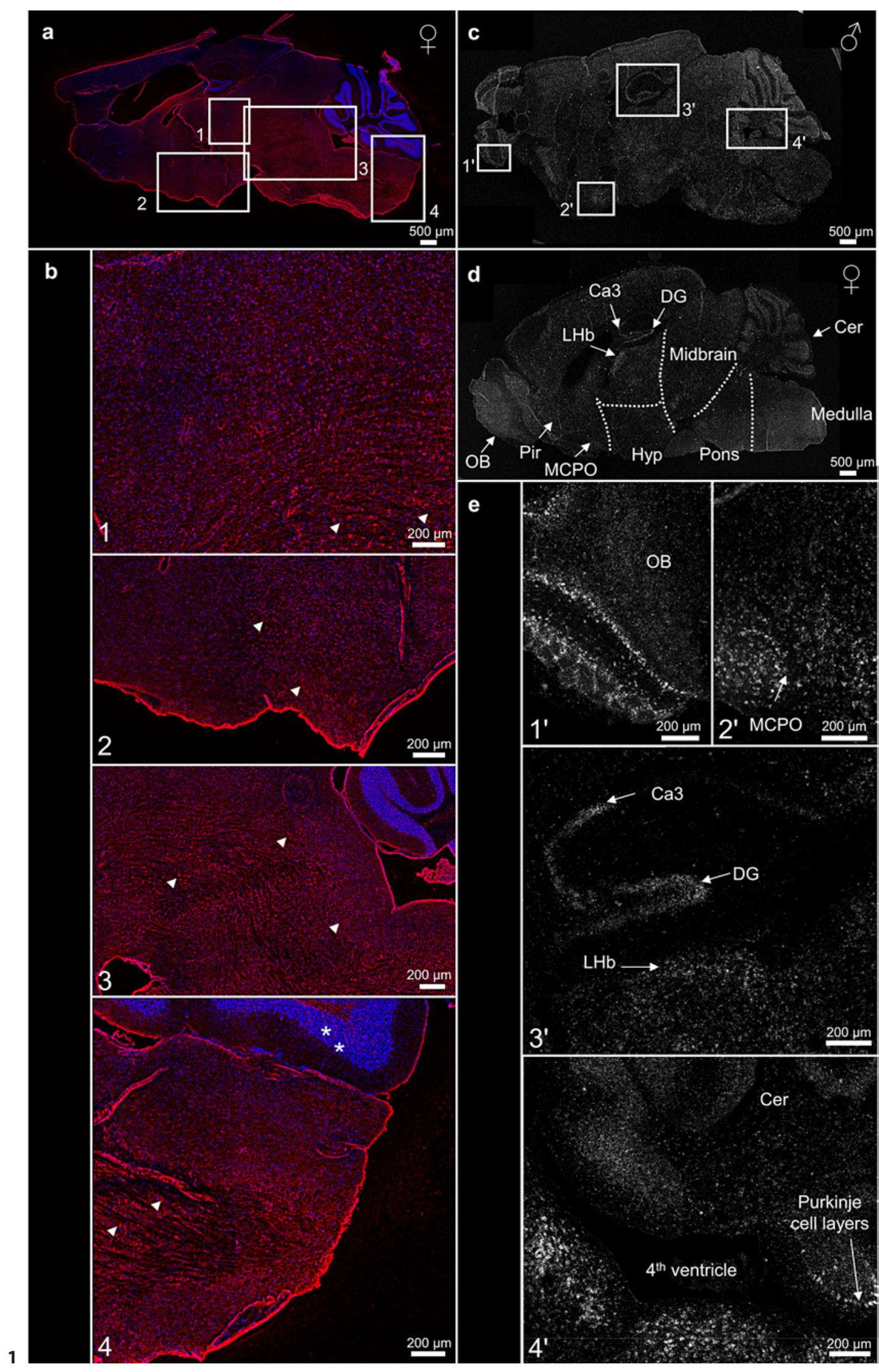

(For legend see next page.) 
Light-Sheet Imaging

Cleared samples were imaged with an Ultramicroscope II (LaVision BioTec, Bielefeld, Germany) using the ImspectorPro software (LaVision BioTec, Bielefeld, Germany). The light sheet was generated by a laser at wavelength of $640 \mathrm{~nm}$ (Coherent Sapphire Laser; LaVision BioTec) and six cylindrical lenses. A binocular stereomicroscope (MXV10; Olympus, Bielefeld Germany) with a $\times 2$ objective (MVPLAPO; Olympus, Bielefeld, Germany) was used at different magnifications $(\times 0.63, \times 2.5, \times 3.2)$. The samples were placed in a horizontal orientation in an imaging reservoir made of $100 \%$ quartz (LaVision BioTec) filled with dibenzyl ether and illuminated from the side by the laser light. Images were acquired with a PCO Edge SCMOS CCD Camera $(2,560 \times 2,160$ Pixel size; LaVision BioTec). The step size in Z-orientation between each image was fixed at $4 \mu \mathrm{m}$ for $\times 0.63$ magnification and $1 \mu \mathrm{m}$ for $\times 2.5$ and $\times 3.2$ magnifications. For the retrorubral field (RRF-A8), substantia nigra (SN-A9), and ventral tegmental area (VTA-A10), mosaic acquisition mode with three fields of view was used.

\section{Thunder Imaging}

Section staining by RNAscope in situ hybridization or immunostaining images were acquired by a DM6 Thunder Upright Fluorescence Microscope with a DFC 9000 GT sCMOS camera (Leica Microsystems, Nanterre, France) and with $\times 10$ objective. Mosaic mode was used to acquire images of whole sections. Post-treatment with the LAS-X software (Leica Microsystems) was done to merge fields of view. Computational clearing, an innovant technology developed by Leica increases the quality of rendering.

\section{Image Processing and Quantitative Assessment of Anatomic}

Structures

Three-dimensional samples were constructed from a Z-series of Ultramicroscope II fluorescence images using the Imaris software, version 9.0.0_64 (http://bitplane.com, Zurich, Switzerland). Three-D pictures and tiff series were obtained using the "Snapshot" and the "animation" tools of the Imaris software. Semi-automatic counting of TH-positive neurons was done with the "spot

Fig. 1. Expression of SELENOT protein and mRNA in the brain of adult WT (Nes-Cre) mice. a Immunolabeling of SELENOT in sagittal sections of adult mouse brain (red). Nuclei are labeled with DAPI (blue). b Magnification of different areas from (a) in the thalamus (b1), hypothalamus (b2), midbrain (b3), and the medulla (b4). Arrowheads indicate cells immunolabeled with antiSELENOT. c In situ hybridization analysis of SELENOT mRNA in a sagittal section of male adult mouse brain. $\mathbf{d}$ In situ hybridization analysis of SELENOT mRNA in a sagittal section of female adult mouse brain. The pyriform nucleus (Pir), the hippocampus (Ca3), the supraoptic nucleus (MCPO), the cerebellum (Cer), the olfactory bulb (OB), the habenula (LHb), and the dentate gyrus (DG) are indicated by arrows, and anatomical structures of the hypothalamus, midbrain, pons, and the medulla are delimited by dotted lines. e Magnification of different areas from $\mathbf{c}$ in the OB $\left(\mathbf{e} \mathbf{1}^{\prime}\right)$, MCPO (e2'), hippocampus Ca3, DG, and LHb (e3') and the 4th ventricle and Cer with the granular and the Purkinje cell layers (e4'). Images were acquired with the Leica Thunder microscope, with $\times 10$ magnification, mosaic reconstruction, and computational clearing treatment.

SELENOT Deficiency Impacts

Catecholamine Neuron Distribution detection" tool of the Imaris software which uses predefined size and intensities thresholds, and a manual verification was used with the "clipping plan" tool as previously described [29, 31]. The cell numbers quantified in WT mice were similar to those previously described [32-34], thus further validating this procedure. Movies were generated with the free software Fiji. Titles and transition additions were done with Movie Maker.

\section{Statistical Analysis}

Data are reported as medians (min-max). The nonparametric Mann-Whitney U test was used. Probability values less than 0.05 were considered significant. Data were analyzed with GraphPad Prism 9 (GraphPad, San Diego, CA, USA).

\section{Results}

\section{SELENOT Distribution in the Mouse Brain}

SELENOT immunostaining was performed on sagittal sections of adult C57bl/6 mouse brain (Fig. 1a). SELENOT exhibited a widespread distribution in the adult brain both in females (Fig. 1a) and males (not shown). Image acquisitions with higher magnification showed the immunostaining of numerous cells in different anatomical zones, including the thalamus (Fig. 1b1), the hypothalamus (Fig. 1b2), midbrain and pons (Fig. 1b3), and the medulla (Fig. 1b4). Within these regions, labeled cells displayed a variable SELENOT staining intensity, with a stronger signal in some areas (Fig. 1b, arrowheads). SELENOT was detected not only in cell bodies but also in nerve fibers, as illustrated in Figure 1b4 (indicated by asterisks). When the immunoreaction was performed in the presence of a SELENOT peptide that was used to generate the antibody, no labeling was observed for SELENOT while a co-labeling with a TH antibody was detected (online suppl. Fig. S1; for all online suppl. material, see www. karger.com/doi/10.1159/000522091).

In situ hybridization analysis confirmed the widespread expression of the SELENOT gene since the mRNA was also detected in various regions of the mouse brain (Fig. 1c, d). The diffuse expression profile of SELENOT mRNA was observed in both male (Fig. 1c) and female (Fig. 1d) mouse brain. Higher mRNA levels could be observed in the olfactory bulb and the glomerular layer (Gl) (Fig. 1e1'), in the pyriform nucleus, in the supraoptic nucleus (MCPO) (Fig. 1e $2^{\prime}$ ), in the hippocampus (Ca3), dentate gyrus, the habenula (Fig. 1e3'), and around the 4 th ventricle and in the cerebellum (Cer) within the granular and the Purkinje cell layers (Fig. 1e4'). Similarly, SELENOT mRNA is abundant in the hypothalamus within the PVN, in the ventral zone of the pons and the medulla (data not shown). In all these areas, cells exhibited a higher density of SELENOT 
Fig. 2. $3 \mathrm{D}$ imaging of $\mathrm{TH}$ immunolabeling in the adult mouse brain. a $3 \mathrm{D}$ sagittal view of TH labeling with anatomical references in adult WT (Nes-Cre) mouse brain. Squares within the image represent anatomical zones magnified in images 1-7 shown below and corresponding to: (1) 3D horizontal view of the AP-A2, (2) 3D coronal view of A5, LC-A6, and A7, (3) 3D coronal view of PAG-A10dc, (4) 3D sagittal view of A11, (5) 3D coronal view of RRF-A8, SN-A9 and VTA-A10, (6) 3D coronal view of the ZI-A13, (7) 3D sagittal view of the Hyp-A12-A14A15 in adult WT (NesCre) mouse brain. b 3D sagittal view of TH labeling with anatomical references in SELENOT-knockout mouse brain. Squares within the image represent anatomical zones magnified in images $1^{\prime}-7^{\prime}$ shown below and corresponding to: $\left(1^{\prime}\right) 3 \mathrm{D}$ horizontal view of the AP-A2, $\left(2^{\prime}\right) 3 \mathrm{D}$ coronal view of A5, LC-A6 and A7, $\left(3^{\prime}\right) 3 \mathrm{D}$ coronal view of PAG-A10dc, $\left(4^{\prime}\right)$ 3D sagittal view of A11, $\left(5^{\prime}\right) 3 \mathrm{D}$ coronal view of RRF-A8, SN-A9 and VTA-A10, $\left(6^{\prime}\right)$ $3 \mathrm{D}$ coronal view of the zona incerta (A13), and $\left(7^{\prime}\right)$ 3D sagittal view of the Hyp-A12-A14-A15 in SELENOT-knockout mouse brain. Acquisitions were performed with the Ultramicroscope II, magnification $\times 0.63(\mathbf{a}, \mathbf{b}),\left(1-6\right.$ and $\left.1^{\prime}-6^{\prime}\right)$ magnification $\times 3.2$, and $\left(7-7^{\prime}\right)$ magnification $\times 2.5$.

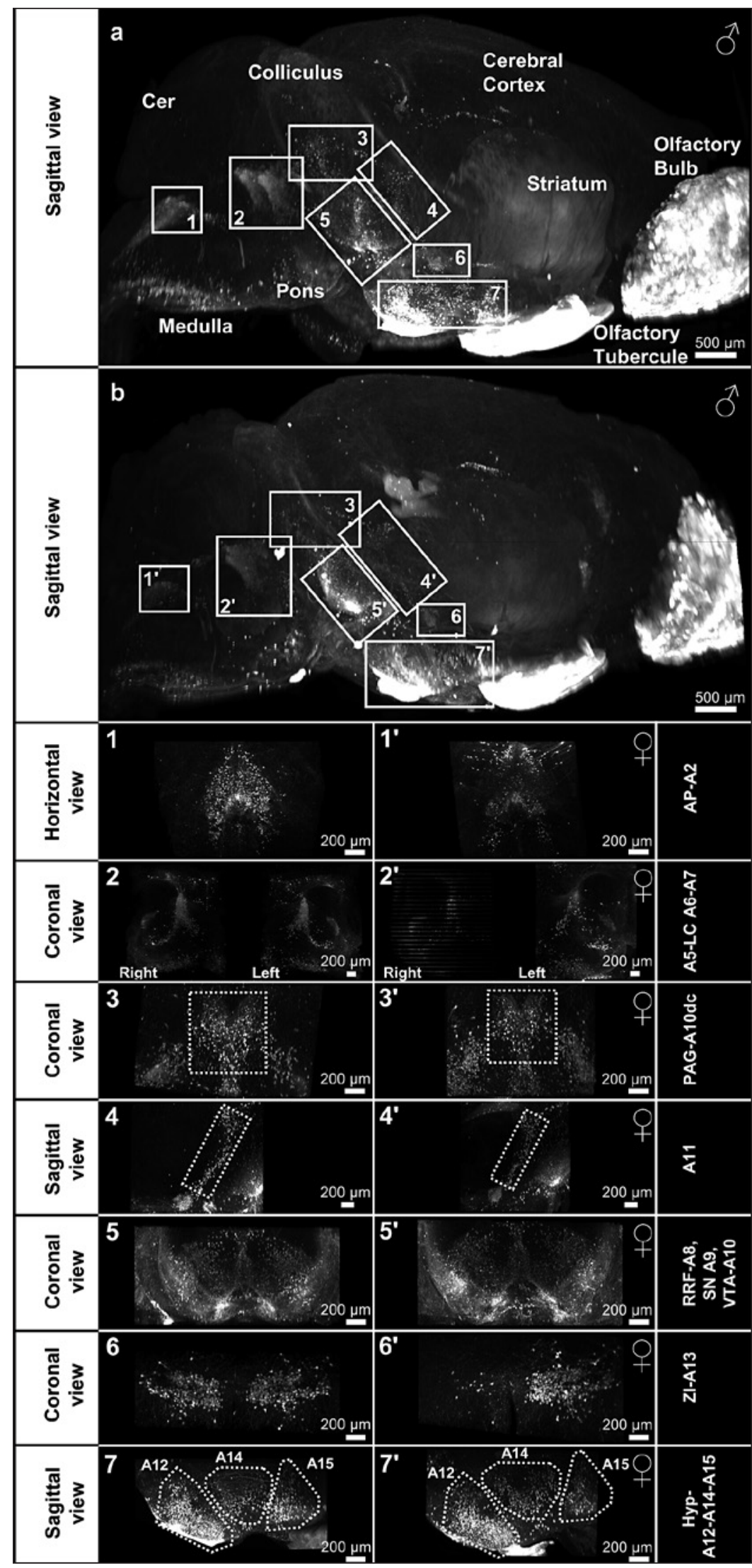

Godefroy/Boukhzar/Mallouki/Carpentier/ Dubessy/Chigr/Tillet/Anouar 


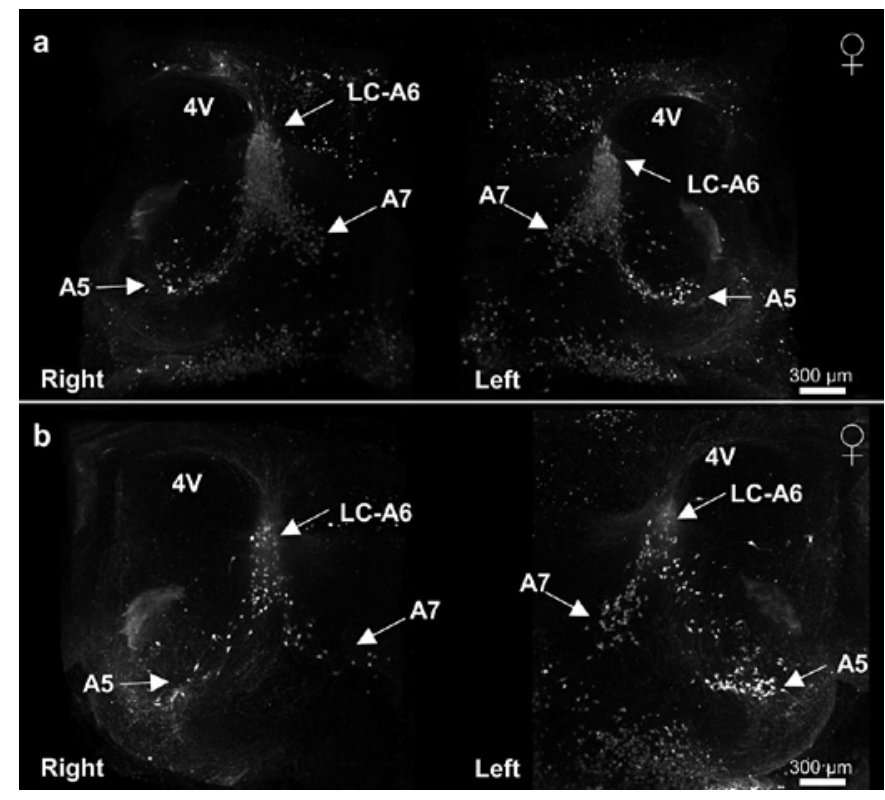

Fig. 3. 3D coronal visualization of TH immunolabeling in different catecholaminergic A5, LC-A6, A7 nuclei in WT (NesCre) (a) in SELENOT-knockout (b) brains of adult mice. Arrows indicate cell groups A5, LC-A6, and A7. 4V corresponds to the 4th ventricle. a The image in the left represents cell groups of the right hemisphere and the image in the right represents cell groups of the left hemisphere in a WT (NesCre) brain. b The image in the left shows cell groups of the right hemisphere and the image in the right shows cell groups of the left hemisphere in a SELENOT-knockout brain. Acquisitions were performed with the Ultramicroscope II: magnification $\times 3.2$.

transcripts per cell as compared to cells in other structures which display a lower level of transcript expression (Fig. 1e).

Distribution of CA Neuron Populations in SELENOTDeficient Mice

Comparison of TH-positive neuronal groups in SELENOT knockout (NesCre-SELENOT ${ }^{f l f l}$ ) $(\mathrm{KO})$ and WT (NesCre) mice was carried out using 3D imaging of in toto immunolabeled mouse brains. This analysis allowed us to determine the distribution of TH-positive neurons in particular regions of interest (Fig. 2, online suppl. Fig. S2-S6; Movie 1). Figure 2 shows the global labeling of the central CA system in adult WT (Fig. 2a) and KO mice (Fig. 2b). The different CA cell groups from A1 to A16 were found in these views of both WT and KO mice as illustrated in Figure 2a, b. However, further observations of the different CA cell groups revealed noticeable differences in cell density between WT and KO mice at the level of area postrema (AP-A2), A5, locus coeruleus (LCA6), A7, A11 cell group (A11), zona incerta (ZI-A13), and
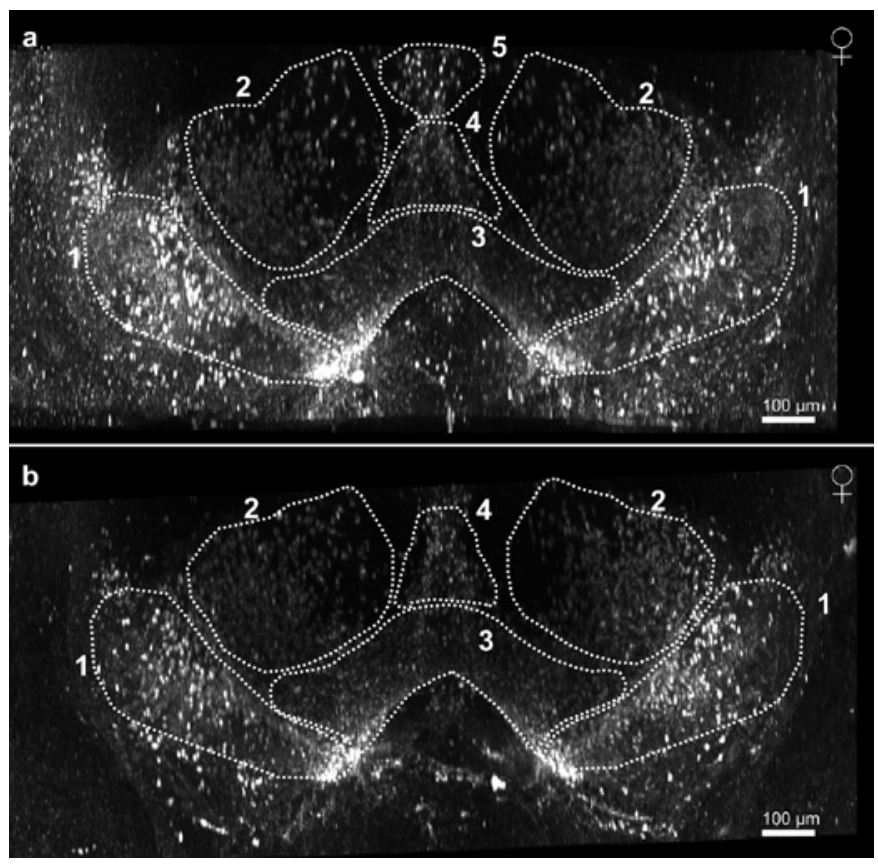

Fig. 4. $3 \mathrm{D}$ coronal visualization of $\mathrm{TH}$ immunolabeling in $\mathrm{SN}-\mathrm{A} 9$ (dotted area 1), RRF-A8 (dotted area 2), VTA-A10 (dotted area 3), the central linear nucleus (Cli) (dotted area 4 ), and the ventral part of the PAG (dotted area 5). a Adult WT (NesCre) brain. b Adult SELENOT-knockout brain. Images were acquired with the Ultramicroscope II; magnification $\times 3.2$.

the hypothalamus (Hyp-A12-A14-A15), but not the RRF-A8, SN-A9, VTA-A10 cell groups (Fig. 2b1-7 for $\mathrm{WT}$ and $\mathrm{b} 1^{\prime}-7^{\prime}$ for KO mice and online suppl. Fig. S2S6). Of note, the ZI-A13 displayed an asymmetrical distribution between the left and the right hemispheres in KO mice (Fig. 2b6') compared to WT mice (Fig. 2b6). It should be noted that the asymmetry was more often observed in females than males, with a variable extent and without a privileged side (data snot shown). Other CA cell groups like A5, LC-A6, A7, RRF-A8, SN-A9, and VTAA10 could not be compared precisely at the cellular level because of the lack of resolution within these areas of high cellular density (Fig. 2b2, b5 for WT, and b2', b5' for KO mice). For instance, LC displayed noticeable cell density differences between WT and KO mice but the high number of CA neurons in this area precludes their quantitative assessment (Fig. 3a, b and online suppl. Movie 2). In contrast, we could not observe any apparent difference in cell distribution at the level of CA groups A8-A10 including the RRF-A8, SN-A9, and the VTA-A10 between WT and $\mathrm{KO}$ mice (Fig. 4a, b and online suppl. Movie 3), but again this observation could not be evaluated quantitatively due to the high cell density in these CA structures. 
Fig. 5. Quantification of TH-positive neurons in the brain of adult male and female WT (NesCre) and SELENOT-knockout mice. Positive neurons were counted semiautomatically in AP-A2, PAG-A10dc, A11, ZI-A13, and Hyp-A12-A14-A15. a Counts were obtained from Hyp-A12-A14-A15 male (median value: 2,717 for $\mathrm{KO}$ mice, $n$ $=6$, vs. 3,619, for WT, $n=9 ; p<0.05)$ and female (median value: 3,254 for KO mice, $n=6$, vs. 3,619 for WT, $n=9$; $p<0.05$ ) mouse brain. $\mathbf{b}$ Counts were obtained from AP-A2 male (median value: 778 for KO mice, $n=6$, vs. 797 for WT, $n=7$ ) and female (median value: 645 for KO mice, $n=$ 7, vs. 911 for WT $n=11$; $p<0.05$ ) mouse brains. c Counts were obtained from A11 male (median value: 407 for KO mice, $n=$ 6, vs. 390 for WT, $n=10$ ) and female (median value: 331 for KO mice, $n=6$, vs. 383 for WT, $n=9$; $p<0.05)$ mouse brains. d Counts were obtained from ZI-A13 male (median value: 997 for KO mice, $n=13$, vs. 1,000 for WT, $n=23$ ) and female (median value: 822 for KO mice, $n=18$, vs. 926 for WT, $n=21 ; p<0.001)$ mouse brains. e Counts were obtained from PAG-A10dc male (median value: 1,122 for $\mathrm{KO}$ mice, $n=6$, vs. 1,184 for WT, $n=9$ ) and female (median value: 1,063 for KO mice, $n=7$, vs. 1,119 for WT, $n=11$ ) mouse brains. Nonparametric Mann-Whitney $\mathrm{U}$ test, ${ }^{*}, p<$ 0.05 ; $* * *, p<0.001$. a

Нyp-A12-A14-A15

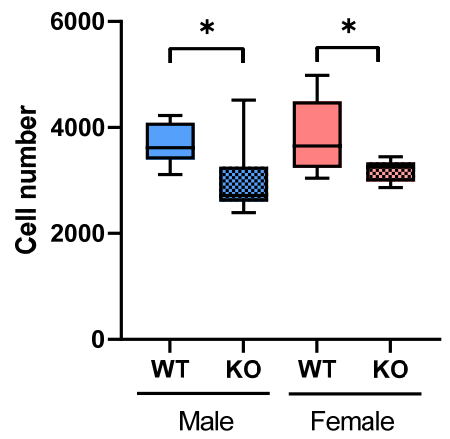

c

A11

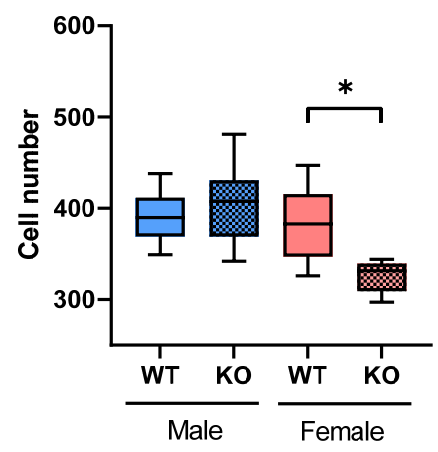

e

PAG-A10dc

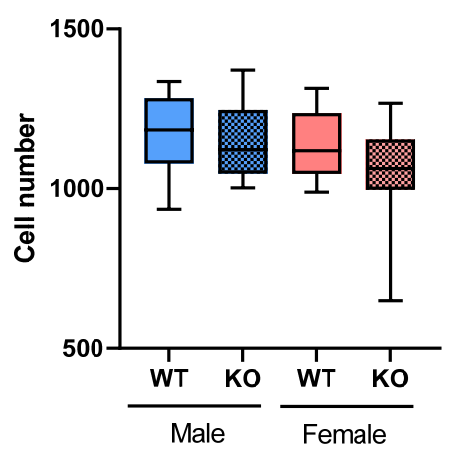

b

AP-A2

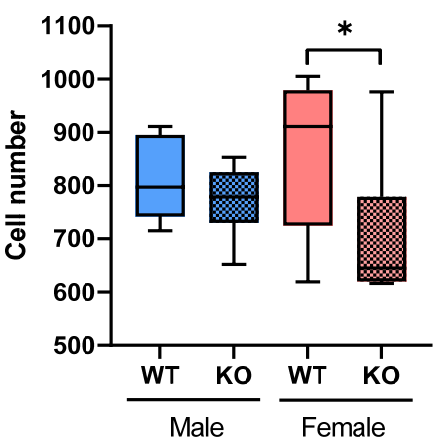

d

ZI-A13

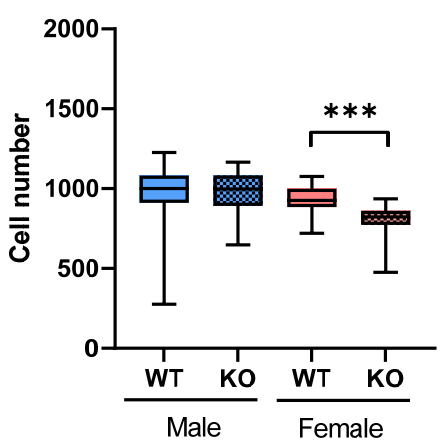

Images with higher magnification were used to quantify the $\mathrm{TH}^{+}$neurons in a semi-automated manner (see online suppl. Fig. S2-S6; Movie 1) in different structures including AP-A2, periaqueductal gray (PAG-A10dc), A11, ZI-A13, and the Hyp-A12-A14-A15 where cells could be easily segmented. The quantitative data are presented in Figure 5. In male mice, a significant decrease in the number of $\mathrm{TH}+$ neurons was only observed in Hyp-
A12-A14-A15 (median value: 2,717 for KO mice, $n=6$, vs. 3,619, for WT, $n=9$; $p<0.05$ ) (Fig. $5 \mathrm{a}$ ), the other regions including the AP-A2 (median value: 778 for KO mice, $n=6$, vs. 797 for WT, $n=7$ ) (Fig. 5b), A11 (median value: 407 for KO mice, $n=6$, vs. 390 for WT, $n=10$ ) (Fig. 5c), ZI-A13 (median value: 997 for KO mice, $n=13$, vs. 1,000 for WT, $n=23$, for the sum of the cells at both left and right sides regardless of the asymmetry) (Fig. 5d), 


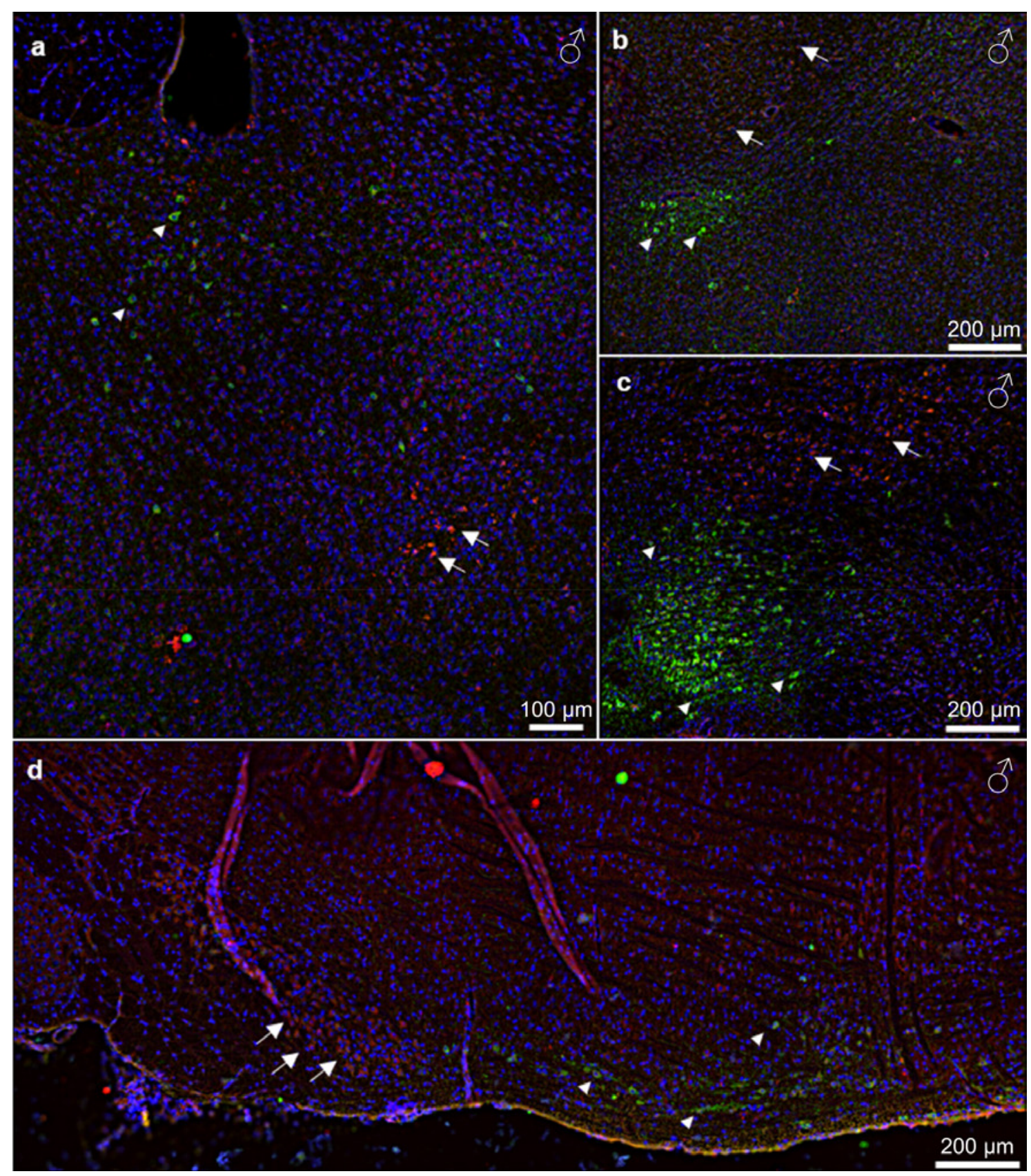

Fig. 6. Co-localization of SELENOT and TH in adult mouse brain. Sagittal sections were immunostained for SELENOT (red, arrows) and TH (green, arrowheads). Nuclei are stained with DAPI (blue). Different anatomical areas are shown: preoptic area (a), ZI-A13 (b), RRF-A8, SN-A9, VTA-A10 (c), and pons (d). Acquisitions were performed with the Thunder microscope, magnification $\times 10$, with mosaic reconstruction and computational clearing treatment.

and PAG-A10dc (median value: 1,122 for KO mice, $n=$ 6, vs. 1,184 for WT, $n=9$ ) (Fig. 5e) did not show significant differences in the number of $\mathrm{TH}+$ neurons between the two mouse strains. In female mice, a significant decrease in $\mathrm{TH}+$ neurons was observed in $\mathrm{KO}$ mice com- pared to WT mice within Hyp-A12-A14-A15 (median value: 3,254 for KO mice, $n=6$, vs. 3,619 for WT, $n=9$; $p<0.05$ ) (Fig. 5a), AP-A2 (median value: 645 for KO mice, $n=7$, vs. 911 for WT $n=11 ; p<0.05$ ) (Fig. 5b), A11 (median value: 331 for KO mice, $n=6$, vs. 383 for $\mathrm{WT}$, 
Fig. 7. Co-localization of SELENOT and TH mRNA in adult mouse brain. In situ hybridization analysis of SELENOT (red, arrows) and $\mathrm{TH}$ (green, arrowheads) mRNA was performed on sagittal sections using the RNA scope technology. Nuclei are stained with DAPI (blue). Cells showing expression of both mRNA are indicated by asterisks. Different anatomical zones are presented: ZI-A13 (a), Cer (b), SN-A9 and VTA-A10 (c), pons (d), SN-A9 (e), and pons (f). Acquisitions were performed with the Thunder microscope, magnification $\times 10$ and $\times 40$, with mosaic reconstruction and computational clearing treatment.

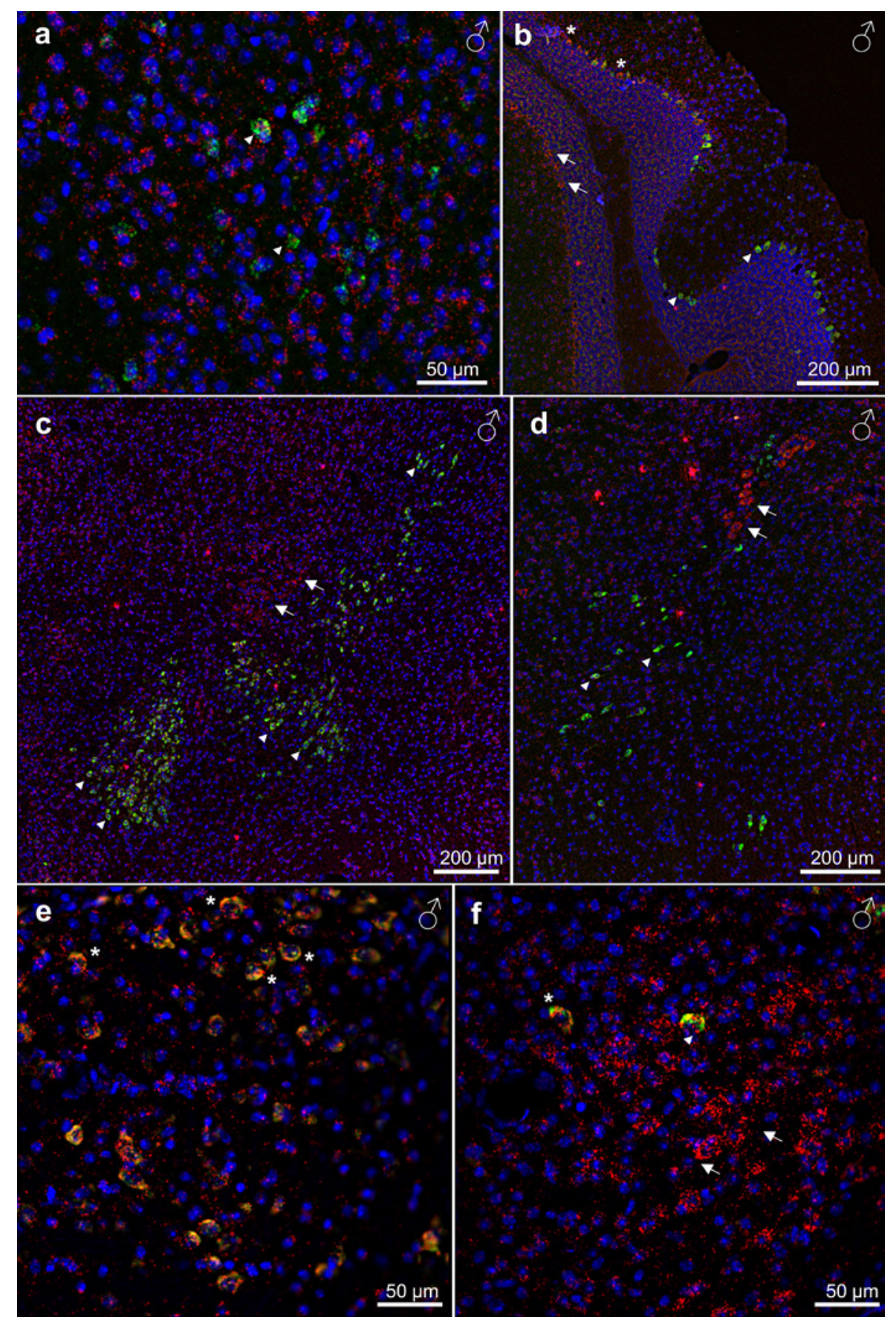

$n=9 ; p<0.05$ ) (Fig. 5c), and ZI-A13 (median value: 822 for KO mice, $n=18$, vs. 926 for WT, $n=21$, for the sum of the cells at both left and right sides regardless of the asymmetry; $p<0.001$ ) (Fig. 5d). In contrast, the anatomical zone of PAG-A10dc did not show a significant difference between $\mathrm{KO}$ (median value: $1,063, n=7$ ) and WT (median value: $1,119, n=11$ ) mice (Fig. 5e).

\section{Comparative Localization of SELENOT and TH in}

\section{Adult Mouse Brain}

In order to compare the neuroanatomical localization of SELENOT and TH, we used fluorescent double labelings either by immunohistochemistry (Fig. 6) or RNA scope in situ hybridization (Fig. 7). In Figure 6, immunohistochemical analysis of TH and SELENOT anatomical 
distribution in adult mouse brain revealed that the two enzymes are highly expressed in different areas of the brain and that there is no apparent cellular colocalization of the two proteins as illustrated in the preoptic area (Fig. 6a), the ZI-A13 (Fig. 6b), RRF-A8 and SN-A9 (Fig. 6c), and the pons (Fig. 6d). However, RNA scope in situ hybridization showed that SELENOT mRNA could be expressed with TH mRNA at the cellular level in different regions of the brain including the ZI-A13 (Fig. 7a), Cer (Fig. 7b), SN-A9, and VTA-A10 (Fig. 7c, e), and pons (Fig. 7d, f) besides other regions with strong mRNA expression for one but not the other gene as also found by immunohistochemistry.

\section{Discussion}

SELENOT has recently attracted a lot of interest because of its essential function in the CNS and endocrine tissues $[10,11]$. This thioredoxin-like selenoenzyme has been initially characterized as a PACAP-stimulated gene in neuroendocrine cells [27], which plays a critical role during development and exerts a neuroprotective function in adulthood. Additional studies revealed the instrumental role of SELENOT in hormone secretion in $\beta$-pancreatic cells [35], corticotroph cells [36], and chromaffin cells [14]. Although the SELENOT gene is essential for mouse development [13] and for the function of neuronal and neuroendocrine cells, no information is available yet on the impact of its gene expression on the development of major neuronal and neuroendocrine cell populations including CA cells where this selenoprotein was initially discovered and where it exerts key functions $[12,14,15,27]$. Different histological techniques including 3D imaging of transparent brains from WT and SELENOT-deficient mice were used in the present study to address the influence of SELENOT on CA neuronal distribution. Analyses by immunohistochemistry and in situ hybridization revealed the widespread expression of SELENOT in the mouse brain, with more intense labeling of anatomical areas including OB, the Gl, Pir, Ca3, dentate gyrus, $\mathrm{MCPO}$, habenula, pons, medulla, granular layers and the Purkinje cell layer of Cer and PVN in Hyp (data not shown). The large distribution of SELENOT in the brain and its known neuroprotective function as demonstrated in our previous studies [12, 13, 15] strongly suggest that this new selenoenzyme stimulated by the trophic neuropeptide PACAP ought to play a fundamental role in the development and function of various nerve cells.

SELENOT Deficiency Impacts

Catecholamine Neuron Distribution
We have then undertaken the characterization of the CA neuronal system in the CNS of conditional, Nes-Cre/ SELENOT ${ }^{f l / f l} \mathrm{KO}$ mice $[12,13]$ in comparison with WT mice, using the iDISCO $^{+}$three-dimensional imaging technique [21,37]. In recent years, a range of clearing methods have been developed to remove lipid and bleach pigment content of a tissue and match the refractive properties of tissue and mounting media to render the tissue transparent. Clearing methods range in complexity from incubating tissue in various solutions to procedures involving electrochemical equipment to facilitate the imaging and 3-dimensional reconstruction of complex structures such as the brain including entire populations of cells. In this regard, light-sheet microscopy techniques used in the present study are particularly suited to imaging cleared tissues as they enable fast acquisition of large $3 \mathrm{D}$ volumes and can include multiangle illumination and imaging $[21,26,38]$. Applying this three-dimensional imaging approach to conditional Nes-Cre/SELENOT ${ }^{f / f l}$ $\mathrm{KO}$ mice revealed alterations of different CA cell groups, including AP-A2, A11, A5, LC-A6, A7, ZI-A13, and HypA12-A14-A15, which showed lower TH cell density compared to WT mice although the brain volume did not differ between WT and SELENOT-deficient mice as assessed by $3 \mathrm{D}$ whole brain imaging (data not shown). This finding is consistent with our previous results showing that brain-SELENOT deficient mice display a reduced cerebral volume at the postnatal stage P7 but not at adulthood, and altered behavioral phenotype, i.e., hyperactivity and anxiety, in adulthood [13]. In addition, the mouse line Nes-Cre/SELENOT ${ }^{f l / f l}$ exhibited a higher vulnerability of dopaminergic neurons to neurotoxin action, emphasizing the crucial role of SELENOT in protecting the CA neuronal system $[12,15,39]$.

Quantification of neuron numbers in different brain regions using tridimensional images offers several advantages over 2D image quantification. First, the counting accuracy is improved since the area of interest is considered in its entirety thus reducing the difficulties inherent to images from serial sections, such as the form of the area to be counted or the erroneous counting of the same neurons several times. Second, the accessibility to different brain zones even within a certain region is also improved. Third, 3D image analysis allows a better delimitation of the region of interest based on the spatial continuation and organization of nerve cells. Using a semi-automated quantification, we measured the density of $\mathrm{TH}^{+}$neurons from 3D images for the cell groups of AP-A2, PAGA10dc, A11, ZI-A13, Hyp-A12-A14-A15. This analysis revealed a significant decrease in the density of $\mathrm{TH}^{+}$cells

Neuroendocrinology 2023;113:193-207 203 
in different areas depending on the sex of the animal. Indeed, male KO mice showed a significant decrease in the number of $\mathrm{TH}^{+}$cells only in the hypothalamus while females exhibited a decrease in AP-A2, A11, ZI-A13, and Hyp-A12-14-15. These results indicate that SELENOT plays a key role in the anatomical distribution of CA cell groups within the CNS likely through a neuroprotective action, and that the extent of this effect is sex-dependent. The protective effect of SELENOT in these neurons may involve its antioxidant properties as we have previously shown that SELENOT is able to protect cortical neuroblasts in culture against oxidative stress and apoptosis [13]. The sexual dimorphism shown by SELENOT for the protection of certain brain CA cell groups remains to be investigated and may underscore a previously unexplained differential antioxidant action of certain factors depending on the sex [40-42]. In contrast to these areas where TH-positive neurons could be quantified in a semiautomated manner from images obtained by light-sheet microscopy, other CA structures with high cell density like LC-A6, RRF-A8, SN-A9, or VTA-A10 could not be quantified due to resolution limitation which hampers cell segmentation for image analysis. This also applies for $3 \mathrm{D}$ imaging of neuronal projections which could be readily observed but whose quantification is rather challenging. To circumvent these limitations, different optical developments are ongoing in order to ameliorate the information obtained from cleared samples [23, 43, 44]. It should be mentioned that the lack of quantitation in these structures does not preclude the description of apparent differences between the two genotypes as indicated for LC-A6 where an apparent decrease of TH-positive neurons could be observed in the 3D images of SELENOTdeficient mice compared to WT. In addition, SELENOT could still play an important role in structures where no difference is observed. Indeed, SELENOT could play a role in the development and maintenance of CA neurons but also in their function in the mature brain as observed in Parkinson's disease models [12].

The groups of CA cells in which SELENOT would exert its protective role have different anatomical localizations and physiological roles. Among the groups of CA neurons that could be quantified, AP is part of the A2 cell group along with NTS (nucleus of the solitary tract) and DMX (dorsal motor nucleus of the X nerve) $[45,46]$. AP noradrenergic nuclei are described as a center for food intake regulation by being the primary relay for the integration of satiety signals coming from the gastrointestinal tract $[47,48]$. This CA cell group, which is sensitive to the variation of different circulating factors, is a direct anatomical link with the NTS $[49,50]$. For instance, amylin secreted by the pancreas stimulates AP neurons leading, via projections to the NTS, to stimulation of $\mathrm{TH}^{+}$neurons which will release DA in the nucleus accumbens and cause the feeling of fullness [51]. Studies are currently ongoing to determine the role of SELENOT in feeding behavior.

The PAG, a nucleus of the midbrain, is involved in many functions. Various studies demonstrated its involvement in the behavioral response to threatening stimuli and in the perception of breathlessness [52]. This nucleus also modulates the perception of pain [53]. Specifically, a localized nucleus grouping within the PAG, adjacent to and surrounding the ventral half of the cerebral aqueduct is identified as the group A10dc cells [54]. Retrograde tracer injections showed an anatomical pathway between the bed nucleus of the stria terminalis and $\mathrm{TH}$ neurons of the A10dc group, suggesting an essential role of dopaminergic neurons in psychiatric, depressive, and anxiety disorders via the neuropeptide corticotropinreleasing factor [55]. Further studies will be required to assess the involvement of SELENOT in such behaviors.

The ZI-A13, described by Auguste Forel hundred years ago, is a neuronal hub involved in many functions: visceral activity, awakening and attention, locomotion, organization of emotion and emotional processing, and nociception [56-58]. This structure is connected with several anatomical areas of the brain: the cortex, the cerebellum, the thalamus, the brainstem, the spinal cord, basal ganglia, amygdala, basal forebrain, and hypothalamus [59]. The ZI-A13 group of cells is linked to the superior colliculus and is a relay to the LC-A6 and the PAG, which gives it an important role in the coordination of movements and avoidance actions $[60,61]$. The reduction in the number of this group of neurons following SELENOT gene inactivation could impact different neurophysiological functions that remain to be identified.

Finally, Hyp-A12-A14-A15 is the link between the autonomic nervous system and the endocrine system. This area of the CNS is involved in many physiological functions to regulate hunger, thirst, sleep, body temperature, emotions, and sexual behavior. Present in large quantities in the hypothalamus, DA plays multiple roles as a neurotransmitter but also as a hormone in the hypothalamopituitary axis [62]. Our preliminary results indicate that SELENOT is required for neuroendocrine functions such as reproduction (manuscript in preparation).

Major CA structures such as SN-A9 or the VTA-A10 did not seem to present significant anatomical differences between WT and SELENOT-deficient mice. It is also possible that minor cell number variations in these struc- 
tures could have been overlooked. However, SELENOT could still play a role in these structures although it would be dispensable for their presence in the brain.

Examination of the cellular expression of $\mathrm{TH}$ and SELENOT in the mouse CNS revealed that these two genes could be co-expressed in some brain nuclei, as assessed by in situ hybridization analysis. However, immunohistochemistry showed that anatomical areas with cells expressing high levels of SELENOT as described above are not colocalized with structures expressing TH. Certain cells with high SELENOT expression levels are found adjacent to areas with TH labeling. Importantly, these data indicate that areas where a reduction in neuron number was observed in brain SELENOT-deficient mice do not necessarily express SELENOT and that the protective effect of the latter could be mediated by other nerve cells. Thus, it is tempting to speculate that SELENOT-expressing cells other that those expressing $\mathrm{TH}$ in a certain brain area, such as GABAergic or glutamatergic neurons (our unpublished observations) may produce trophic factors that would support the development and maintenance of TH neurons which do not express SELENOT.

In conclusion, this study revealed the widespread expression of SELENOT with higher expression in different brain nuclei. Its deficiency in the mouse Nes-Cre/SELE$\mathrm{NOT}^{f l f l}$ has a major impact on CA neurons in several areas where neuron number was decreased as revealed by in toto whole mount 3D-imaging. Together, these data strongly suggest that SELENOT is a key selenoprotein for the integrity of the CNS, whose activity as a redox guardian of the ER involved in protein maturation $[10,11,35]$ sustains CA neuron survival and probably adequate neurotransmitter genesis. Therefore, this SELENOT activity is likely to be required for various physiological, behavioral, and cognitive functions that will be elucidated in future studies. Since SELENOT has been previously shown to be involved in neuroendocrine cell function, its impact on neuroendocrine regulations through CA release should be further considered and investigated.

\section{Statement of Ethics}

The experiments on animals were performed according to the rules of our institutions and following the guidelines of the European Community for Experimental Animal Use (Directive 2010/63/EU as amended by Regulation [EU] 2019/1010). All procedures using animals were approved by the Normandy Ethics Committee for Animal Care and Use and the French Ministry of Research (Authorization No. 16178-2018071817069319).

\section{Conflict of Interest Statement}

The authors declare no competing interest.

\section{Funding Sources}

This work was supported by grants from the University of Rouen Normandie (DC2N), INSERM (U1239), and the Regional council of Normandie and the European Community FEDER program (Europe gets involved in regional development through the ERDF program). Images were acquired in PRIMACEN, the cell imaging platform of Normandy.

\section{Author Contributions}

David Godefroy performed the 3D imaging and RNA scope in situ hybridization, planned experiments, analyzed data, and prepared the figures and the manuscript; Loubna Boukhzar performed immunohistochemistry; Ben Yamine Mallouki maintained animal colonies; Emmanuelle Carpentier was involved in RNA scope in situ hybridization; Christophe Dubessy and Fatiha Chigr contributed to experiment design and analyzed the data; and Youssef Anouar planned the experiments, analyzed and interpreted data, and wrote the manuscript.

\section{Data Availability Statement}

All data generated or analyzed during this study are included in this article. Further enquiries can be directed to the corresponding author.

\section{References}

SELENOT Deficiency Impacts

Catecholamine Neuron Distribution
1 Santana Y, Montejo AL, Martín J, LLorca G, Bueno G, Blázquez JL. Understanding the mechanism of antidepressant-related sexual dysfunction: inhibition of tyrosine hydroxylase in dopaminergic neurons after treatment with paroxetine but not with agomelatine in male rats. J Clin Med. 2019;8(2):133.

2 Douma EH, de Kloet ER. Stress-induced plasticity and functioning of ventral tegmental dopamine neurons. Neurosci Biobehav Rev. 2020;108:48-77.
3 Ljungberg T, Apicella P, Schultz W. Responses of monkey dopamine neurons during learning of behavioral reactions. J Neurophysiol. 1992;67(1):145-63.

4 Romo R, Schultz W. Dopamine neurons of the monkey midbrain: contingencies of responses to active touch during self-initiated arm movements. J Neurophysiol. 1990;63(3): 592-606. 
5 Hökfelt T. Distributional of tyrosine hydroxylase- immunoreactive neurons in the rat brain. Handb Chem Neuroanat. 1984;2:277379.

6 Dahlstroem A, Fuxe K. Evidence for the existence of monoamine-containing neurons in the central nervous system. I. Demonstration of monoamines in the cell bodies of brain stem neurons. Acta Physiol Scand Suppl. 1964;Suppl 232:1-55.

7 Smeets WJ, González A. Catecholamine systems in the brain of vertebrates: new perspectives through a comparative approach. Brain Res Brain Res Rev. 2000;33(2-3):308-79.

8 Hetz C. Adapting the proteostasis capacity to sustain brain healthspan. Cell. 2021;184(6): 1545-60.

9 Valdés P, Mercado G, Vidal RL, Molina C, Parsons G, Court FA, et al. Control of dopaminergic neuron survival by the unfolded protein response transcription factor XBP1. Proc Natl Acad Sci U S A. 2014;111(18):6804-9.

10 Anouar Y, Lihrmann I, Falluel-Morel A, Boukhzar L. Selenoprotein T is a key player in ER proteostasis, endocrine homeostasis and neuroprotection. Free Radic Biol Med. 2018; 127:145-52.

11 Pothion H, Jehan C, Tostivint H, Cartier D, Bucharles C, Falluel-Morel A, et al. An essential oxidoreductase serving as a guardian of endoplasmic reticulum homeostasis. Antioxidants Redox Signal. 2020;33(17):1257-75.

12 Boukhzar L, Hamieh A, Cartier D, Tanguy Y, Alsharif I, Castex M, et al. Selenoprotein T exerts an essential oxidoreductase activity that protects dopaminergic neurons in mouse models of Parkinson's disease. Antioxidants Redox Signal. 2016;24(11):557-74.

13 Castex MT, Arabo A, Bénard M, Roy V, Le Joncour V, Prévost G, et al. Selenoprotein T deficiency leads to neurodevelopmental abnormalities and hyperactive behavior in mice. Mol Neurobiol. 2016;53(9):5818-32.

14 Abid H, Cartier D, Hamieh A, François-Bellan AM, Bucharles C, Pothion H, et al. AMPK activation of PGC-1 $\alpha /$ NRF-1-dependent SELENOT gene transcription promotes PACAP-induced neuroendocrine cell differentiation through tolerance to oxidative stress. Mol Neurobiol. 2019 Jun;56(6):4086-101.

15 Alsharif I, Boukhzar L, Lefranc B, Godefroy D, Aury-Landas J, do Rego JL, et al. Cell-penetrating, antioxidant SELENOT mimetic protects dopaminergic neurons and ameliorates motor dysfunction in Parkinson's disease animal models. Redox Biol. 2021;40:101839.

16 Goridis C, Rohrer H. Specification of catecholaminergic and serotonergic neurons. Nat Rev Neurosci. 2002;3(7):531-41.

17 Falck B, Hillarp NÅ, Thieme G, Torp A. Fluorescence of catechol amines and related compounds condensed with formaldehyde. J Histochem Cytochem. 1962 May;10(3):348-54.

18 Selzer ME. Variability in maps of identified neurons in the sea Lamprey spinal cord examined by a wholemount technique. Brain Res. 1979;163(2):181-93.
19 Aitken AR. The preparation and use of embryonic brain wholemounts. J Neurosci Methods. 1987;19(4):297-304.

20 Aitken AR, Sandeman RE, Sandeman DC. Preparation of immunoperoxidase-labelled wholemounts of invertebrate brains. J Neurosci Methods. 1987;21(1):1-7.

21 Renier N, Wu Z, Simon DJ, Yang J, Ariel P, Tessier-Lavigne M. IDISCO: a simple, rapid method to immunolabel large tissue samples for volume imaging. Cell. 2014;159(4):896910.

22 Ertürk A, Becker K, Jährling N, Mauch CP, Hojer CD, Egen JG, et al. Three-dimensional imaging of solvent-cleared organs using 3DISCO. Nat Protoc. 2012;7(11):1983-95.

23 Molbay M, Kolabas ZI, Todorov MI, Ohn T, Ertürk A. A guidebook for DISCO tissue clearing. Mol Syst Biol. 2021;17(3):1-21.

24 Voie AH, Burns DH, Spelman FA. Orthogonal plane fluorescence optical sectioning: three dimensional imaging of macroscopic biological specimens. J Microsc. 1993;170(3): 229-36.

25 Dodt HU, Leischner U, Schierloh A, Jährling N, Mauch CP, Deininger K, et al. Ultramicroscopy: three-dimensional visualization of neuronal networks in the whole mouse brain. Nat Methods. 2007;4(4):331-6.

26 Godefroy D, Boukhzar L, Dubessy C, Montero-Hadjadje M, Yon L, Eiden LE, et al. Three-dimensional mapping of tyrosine hydroxylase in the transparent brain and adrenal of prenatal and pre-weaning mice: comprehensive methodological flowchart and quantitative aspects of 3D mapping. J Neurosci Methods. 2020;335:108596.

27 Grumolato L, Ghzili H, Hadjadje MM, Gasman S, Lesage J, Tanguy Y, et al. Selenoprotein $\mathrm{T}$ is a PACAP regulated gene involved in intracellular Ca2+ mobilization and neuroendocrine secretion. FASEB J. 2008;22(6):1756-68.

28 Dubois MP. Les cellules corticotropes de l'hypophyse des bovins, ovins et porcins mise en évidence par immunofluorescence et caractères cytologiques. Ann Biol Anim Bioch Biophys. 1971;11(4):589-624.

29 Godefroy D, Dominici C, Hardin-Pouzet H, Anouar Y, Melik-Parsadaniantz S, Rostène $\mathrm{W}$, et al. Three-dimensional distribution of tyrosine hydroxylase, vasopressin and oxytocin neurones in the transparent postnatal mouse brain. J Neuroendocrinol. 2017; 29(12):1-10.

30 Godefroy D, Rostène W, Anouar Y, Goazigo AR. Tyrosine-hydroxylase immunoreactivity in the mouse transparent brain and adrenal glands. J Neural Transm. 2019;126(4):36775.

31 El Nachef WN, Hu C, Bronner ME. Whole gut imaging allows quantification of all enteric neurons in the adult zebrafish intestine. Neurogastroenterol Motil. 2022;34(4):e14292.

32 Skagerberg G, Lindvall O. Organization of diencephalic dopamine neurones projecting to the spinal cord in the rat. Brain Res. 1985; 342(2):340-51.
33 Grimm J, Mueller A, Hefti F, Rosenthal A. Molecular basis for catecholaminergic neuron diversity. Proc Natl Acad Sci U S A. 2004; 101(38):13891-6.

34 Koblinger K, Füzesi T, Ejdrygiewicz J, Krajacic A, Bains JS, Whelan PJ. Characterization of A11 neurons projecting to the spinal cord of mice. PLoS One. 2014;9(10):e109636-12.

35 Prevost G, Arabo A, Jian L, Quelennec E, Cartier D, Hassan S, et al. The PACAP-regulated gene selenoprotein $\mathrm{T}$ is abundantly expressed in mouse and human $\beta$-cells and its targeted inactivation impairs glucose tolerance. Endocrinology. 2013; 154(10):3796806.

36 Hamieh A, Cartier D, Abid H, Calas A, Burel $\mathrm{C}$, Bucharles $\mathrm{C}$, et al. Selenoprotein $\mathrm{T}$ is a novel OST subunit that regulates UPR signaling and hormone secretion. EMBO Rep. 2017; 18(11):1935-46.

37 Renier N, Adams EL, Kirst C, Wu Z, Azevedo $\mathrm{R}$, Kohl J, et al. Mapping of brain activity by automated volume analysis of immediate early genes. Cell. 2016;165(7):1789-802.

38 Belle M, Godefroy D, Dominici C, HeitzMarchaland C, Zelina P, Hellal F, et al. A simple method for $3 \mathrm{D}$ analysis of immunolabeled axonal tracts in a transparent nervous system. Cell Rep. 2014 Nov;9(4):1191-201.

39 Shao ZQ, Zhang X, Fan HH, Wang XS, Wu HM, Zhang L, et al. Selenoprotein T promotes proliferation and G1-to-S Transition in SKN-SH Cells: implications in Parkinson's disease. J Nutr. 2019;149(12):2110-9.

40 Beeson PB. Age and sex associations of 40 autoimmune diseases. Am J Med. 1994 May; 96(5):457-62.

41 Taqi MO, Saeed-Zidane M, Gebremedhn S, Salilew-Wondim D, Khdrawy O, Rings F, et al. Sexual dimorphic expression and release of transcription factors in bovine embryos exposed to oxidative stress. Mol Reprod Dev. 2019;86(12):2005-19.

42 Di Florio DN, Sin J, Coronado MJ, Atwal PS, Fairweather D. Sex differences in inflammation, redox biology, mitochondria and autoimmunity. Redox Biol. 2020;31:101482.

43 Almagro J, Messal HA, Zaw Thin M, van Rheenen J, Behrens A. Tissue clearing to examine tumour complexity in three dimensions. Nat Rev Cancer. 2021;21(11):718.

44 Vieites-Prado A, Renier N. Tissue clearing and 3D imaging in developmental biology. Development. 2021 Sep;148(18):dev199369.

45 Blouet C. Le rôle du noyau du tractus solitaire dans la détection et l'intégration de multiples signaux métaboliques. Méd Sci. 2013;29(5): 449-52.

46 Rinaman L. Oxytocinergic inputs to the nucleus of the solitary tract and dorsal motor nucleus of the vagus in neonatal rats. J Comp Neurol. 1998;399(1):101-9.

47 Kachidian P, Pickel VM. Localization of tyrosine hydroxylase in neuronal targets and efferents of the area postrema in the nucleus tractus solitarii of the rat. J Comp Neurol. 1993 Mar 15;329(3):337-53. 
48 Reiner DJ, Mietlicki-Baase EG, McGrath LE, Zimmer DJ, Bence KK, Sousa GL, et al. Astrocytes regulate GLP-1 receptor-mediated effects on energy balance. J Neurosci. 2016; 36(12):3531-40.

49 Roman CW, Derkach VA, Palmiter RD. Genetically and functionally defined NTS to PBN brain circuits mediating anorexia. Nat Commun. 2016;7:11905-11.

50 Cunningham ET, Miselis RR, Sawchenko PE. The relationship of efferent projections from the area postrema to vagal motor and brain stem catecholamine-containing cell groups: an axonal transport and immunohistochemical study in the rat. Neuroscience. 1994;58(3): 635-48.

51 Potes CS, Turek VF, Cole RL, Vu C, Roland BL, Roth JD, et al. Noradrenergic neurons of the area postrema mediate amylin's hypophagic action. Am J Physiol. 2010;299(2):623-31.

52 Faull OK, Subramanian HH, Ezra M, Pattinson KTS. The midbrain periaqueductal gray as an integrative and interoceptive neural structure for breathing. Neurosci Biobehav Rev. 2019;98:135-44.
53 Skinner GO, Damasceno F, Gomes A, De Almeida OMMS. Pharmacology, Biochemistry and Behavior Increased pain perception and attenuated opioid antinociception in paradoxical sleep-deprived rats are associated with reduced tyrosine hydroxylase staining in the periaqueductal gray matter and are reversed by L-D. Pharmacol Biochem Behav. 2011;99(1):94-9.

54 Marcos P, Arroyo-Jimenez MM, Lozano G, Aguilar LA, Coveñas R. Mapping of tyrosine hydroxylase in the alpaca (Lama pacos) brainstem and colocalization with CGRP. J Chem Neuroanat. 2011;41(2):63-72.

55 Meloni EG, Gerety LP, Knoll AT, Cohen BM, Carlezon WA. Behavioral and anatomical interactions between dopamine and corticotropin-releasing factor in the rat. J Neurosci. 2006;26(14):3855-63.

56 Coenen VA, Schlaepfer TE, Maedler B, Panksepp J. Cross-species affective functions of the medial forebrain bundle-Implications for the treatment of affective pain and depression in humans. Neurosci Biobehav Rev. 2011;35(9): 1971-81.

57 Moriya S, Yamashita A, Masukawa D, Setoyama H, Hwang Y, Yamanaka A, et al. Involvement of A13 dopaminergic neurons located in the zona incerta in nociceptive processing: a fiber photometry study. Mol Brain. 2020; 13(1):4-7.
58 Wang X, Chou XL, Zhang LI, Tao HW. Zona incerta: an integrative node for global behavioral modulation. Trends Neurosci. 2020; 43(2):82-7.

59 Mitrofanis J. Some certainty for the "zone of uncertainty"? Exploring the function of the zona incerta. Neuroscience. 2005;130(1):115.

60 Essig J, Felsen G. Warning! Dopaminergic modulation of the superior colliculus. Trends Neurosci. 2016;39(1):2-4.

61 Bolton AD, Murata Y, Kirchner R, Kim SY, Young A, Dang T, et al. A diencephalic dopamine source provides input to the superior colliculus, where D1 and D2 receptors segregate to distinct functional zones. Cell Rep. 2015;13(5):1003-15.

62 Kawano H, Daikoku S. Functional topography of the rat hypothalamic dopamine neuron systems: retrograde tracing and immunohistochemical study. J Comp Neurol. 1987; 265(2):242-53. 